\title{
New categories for traditional medicine in the Economic Botany Data Collection Standard
}

\author{
Marta Gruca ${ }^{a}$, Rodrigo Cámara-Leret ${ }^{\mathrm{b}}$, Manuel J. Macía ${ }^{\mathrm{b}}$, Henrik Balslev ${ }^{\mathrm{a}, *}$ \\ a Department of Bioscience - Research Group Ecoinformatics and Biodiversity, Aarhus University, Build. 1540, Ny Munkegade 114, \\ DK-8000 Aarhus C, Denmark \\ b Departamento de Biología, Área de Botánica, Universidad Autónoma de Madrid, Calle Darwin 2, ES- 28049 Madrid, Spain
}

\section{A R T I C L E I N F O}

\section{Article history:}

Received 3 May 2014

Received in revised form

13 June 2014

Accepted 16 June 2014

Available online 24 June 2014

\section{Keywords:}

Ethnobotany

Ethnomedicine

Traditional knowledge

Medicinal plant classification

Ritual and magical uses

Cultural diseases and disorders

\begin{abstract}
A B S T R A C T
The Economic Botany Data Collection Standard (EBDCS) has been successfully followed by ethnobotanists investigating plant uses in many parts of the world. However, we have encountered some cases in our study of traditional medicine where the standard seems incomplete and inaccurate when it is applied to plant uses of rural or indigenous societies in developing countries. We propose two categories to be added to the EBDCS: Cultural Diseases and Disorders, and Ritual/Magical Uses. Adding these categories, we believe will give a more accurate insight into traditional medicine and will contribute to developing an integrative ethnomedicinal data collection protocol, which will make ethnomedicinal studies more comparable.
\end{abstract}

(c) 2014 Elsevier Ireland Ltd. All rights reserved.
The Economic Botany Data Collection Standard (EBDCS) proposed by Cook (1995) was a major step forward in comparative ethnobotany and it has been successfully followed by ethnobotanists investigating plant uses in many parts of the world. The major advantage of standardizing a plant use terminology is that it allows the use of raw data in quantitative ways, which makes ethnobotanical studies from many regions and cultural settings apt for integration and comparison. In most cases the EBDCS can be applied successfully, and information about plant uses from different parts of the world can be effectively translated into accepted scientific terms. However, we have encountered some cases in our study of traditional medicine where the standard seems incomplete and inaccurate when it is applied to plant uses of rural or indigenous societies in developing countries. Not all plant uses in traditional medicine can be associated with commonly known diseases, and therefore be analyzed based on conventional medical system categories offered by the EBDCS. We are aware that the Standard is being improved and new categories are being considered to fill gaps and remove discrepancies. With this paper we would like to contribute to that process and we propose complementary ideas for the field of ethnomedicine. We propose two categories (Cultural Diseases and Disorders, and Ritual/Magical Uses) to be added to the

\footnotetext{
* Corresponding author.

E-mail address: henrik.balslev@biology.au.dk (H. Balslev).
}

EBDCS, which we believe will give a more accurate insight into traditional medicine.

Traditional medicine is the sum of knowledge and practices, whether explicable or not, used in diagnosis, prevention, alleviation and treatment of physical and mental or social diseases, and it may rely exclusively on past experience and observation (WHO, 2000). Furthermore, traditional medicine recognizes that diseases can be due to supernatural causes arising from the displeasure of ancestral gods, evil spirits or the effects of witchcraft. On the whole, it is a system with great emphasis on psychological and socio-pathic causes of disease and it is completely responsive to man in his psycho-physical and socio-political reality and unity (Tempesta, 1980; Sofowora, 1993; Mafimisebi and Oguntade, 2010).

The spiritual framework is an inextricable part of traditional medicinal practice. Therefore, placing folk remedies in Western medicinal categories becomes difficult since etiology of diseases and treatment are highly distinct and difficult to compare (Landy, 1985). While traditional medicine comprehends health disorders caused by witchcraft, sorcery, and other supernatural forces, and deals with these mystical powers in order to get rid of bothersome symptoms, Western medical system only recognizes scientific facts and natural causation of disease. Thus, separating plant remedies from the ritual practices and spiritual context only exposes a part of traditional medical knowledge. Furthermore, it is impossible to draw a clear line between magical and rational, or spiritual and scientific and it is difficult to predict whether a plant remedy will 
prove to be effective and why. Some medicinal plants, just like placebo, can be efficacious without biologically active components (Moerman, 2007). There are cultural and psychological factors involved in responses to inert treatments, and some medicinal plants can be effective because of their powerful and meaningful appearance (color, shape, scent, taste) rather than their specific pharmacology.

A model presented by Pretorius (1991) illustrates the link between some aspects of the traditional medicinal system to the modern medical system (Fig. 1a).

In this model, surgical aspects of modern medicine are correlated with ritual manipulations such as bone-setting, blood-letting and extraction of foreign objects. Likewise, some traditional taboos correspond to preventive health measures in the modern medical system. These comparisons only show how radically different the foundations of the two systems are, both when it concerns treatment methods and spiritual principles. It is therefore impossible to make a direct translation and standardize both systems by the same categories.

One of the obstacles of EBDCS is that diseases and health disorders are presented unambiguously disregarding socially and culturally important factors that may underlie them. In addition, there are no use categories for alternative diagnoses and therapies practiced in a traditional medical system. Therefore, it is impossible to describe a comprehensive idea of how traditional medicine functions, and what it deals with, using the EBDCS.

Cultural diseases and disorders are health disorders believed to emerge from magical-supernatural forces, and recognized by a specific local cultural group or ethnicity. These illnesses or afflictions usually have local names and are folk-diagnostic-categories that provide logic to certain repetitive and troubling sets of experiences (Lee and Balick, 2003). In the literature this phenomenon is also known as culture bound syndromes/illnesses (Carel and Cooper, 2010; Mathez-Stiefel et al., 2012). We have already

A

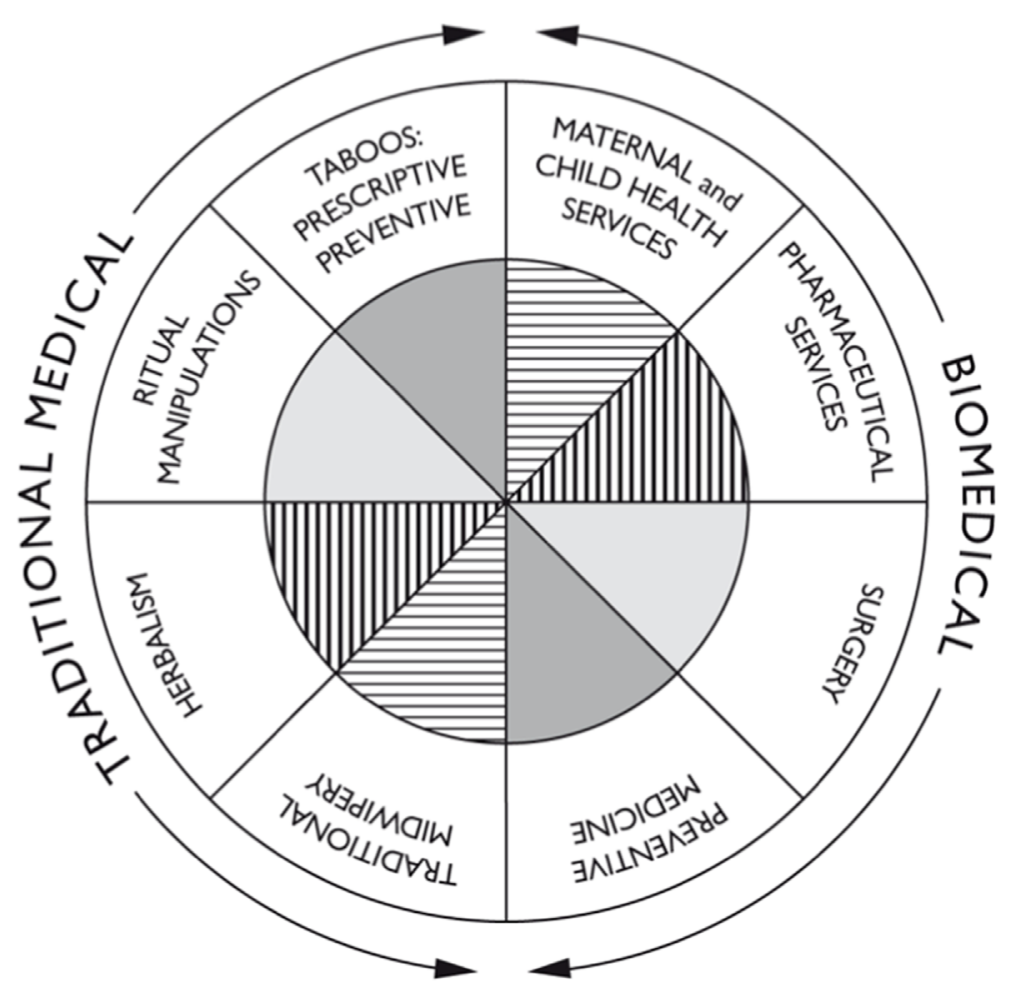

B

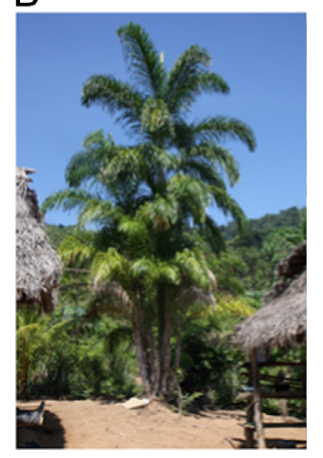

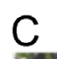

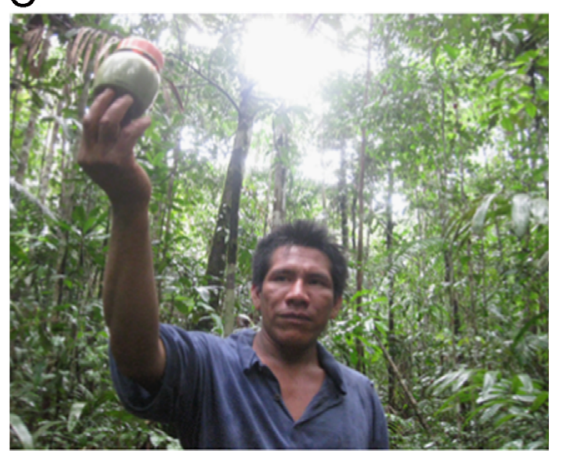

D

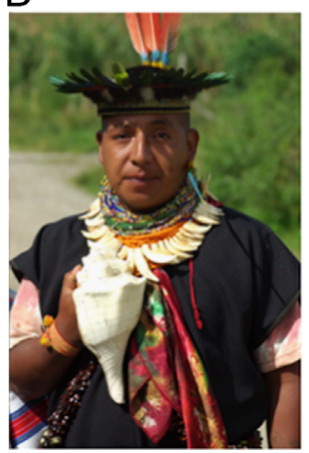

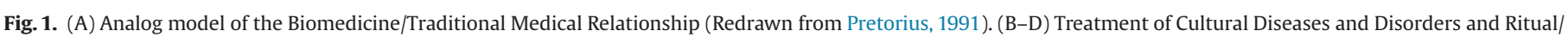

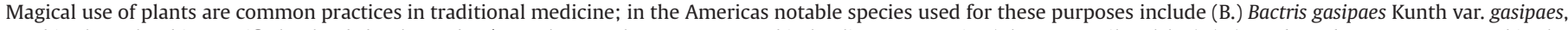

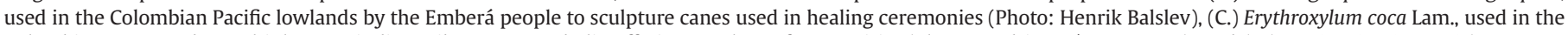

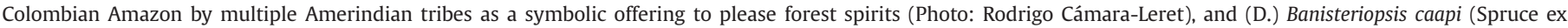
Griseb.) C.V. Morton, used in the Andean-Amazon piedmont as a hallucinogen for diagnosing diseases (Photo: Rodrigo Cámara-Leret). 
implemented this use category in a standard protocol for gathering palm ethnobotanical data, and successfully applied it in a quantitative review of palm uses in northwestern South America (Paniagua-Zambrana et al., 2010; Cámara-Leret et al., 2011; Macía et al., 2011). Cultural-bound health issues concern both diseases and their causation, for example witchcraft, ancestors-gods, deities or sorcerers. These punitive nonhuman forces are usually associated with anger, jealousy, and greed; the patient often becomes a victim, and the therapy is a matter of healing social relationships in order to liberate the patient from his or her suffering. Rituals accompanied by incantations, spells, prayers and music are involved in the entire healing process, beginning with finding the etiology of disease and continuing with protective amulets given to convalescents. Thus, medical rituals do not only apply to social/cultural uses (as now included in EBDCS), but should also be considered when studying traditional medicines, as they often influence human health (Lee and Balick, 2002). This has already been noted by Sosnowska and Balslev (2009) who applied to EBDCS the additional category of Social Uses in their review of American palm ethnomedicine, taking into consideration healing rituals and local beliefs on health and illness.

It must be remembered that the users have a logic, which only becomes apparent when it is deciphered on its own terms, that is from the users' point of view. Because in traditional medicinal practice it is frequently the cause of disease and not the symptoms that triggers the treatment, traditional medical wisdom should be evaluated under its own rules and standards. Here we propose two additional EBDCS categories that in our opinion will contribute to more complete data collection when studying traditional medicines.

A new category "Cultural Diseases and Disorders" should be added to level 2 states under level 1 state Medicines.

Some examples of health disorders under this category and their causation are:

- Susto (fright sickness) - in Ecuador highlands people suffer from susto, which can be caused by a frightening experience such as unexpected encounter with a spirit, scary dreams, or an accident; and, if severe, it may result in loss of the soul (Cavender and Albán, 2009). The departure of the soul is dangerous because malevolent forces are attracted to and suffuse a soulless body. Symptoms of susto include loss of appetite, crying, stomachache, insomnia, and bad dreams. An example of treatment involves ingesting an infusion made from leaves of Ambrosia arborescens Mill. (Cavender and Albán, 2009).

- Mal de ojo (evil eye) - in the Colombian Pacific region Afroamericans suffer from mal de ojo, which is caused by an envious malevolent look (Cámara-Leret, unpublished). To treat patients dried leaves of the palm Manicaria saccifera Gaertn. are burnt near the patient.

- Malos vientos (bad winds) - in Ecuador highlands malos vientos are believed to be caused by a person's exposure to malevolent, destructive force that is transmitted through wind (Cavender and Albán, 2009). One treatment involves brushing the patient's body with a whole plant of Minthostachys mollis Kunth.

- In Ghana, a decoction from Borassus aethiopum Mart. roots is used by the Kokomba in the treatment of any disease caused by a curse (Gruca, unpublished).

Some other examples of Cultural Diseases and Disorders can be found in Lee and Balick (2003), Macía et al. (2005), Stekelenburg et al. (2005).

There is a debate whether Cultural Diseases and Disorders should actually be treated as distinct conditions, or rather as equivalents or variants of universally occurring disorders (Landy, 1985). Some episodes resemble those recognized by Western medicine, for example symptoms of susto or mal de ojo can be seen as a type of mental illness, such as paranoia or psychosis. Some cultural diseases may not even be considered health disorders but merely normal, though unpleasant, biological and psychological states, such as justified sadness (Cooper, 2010). Furthermore, the etiology of Cultural Diseases and Disorders is radically different from scientifically recognized disorders, and is primarily spiritual. Actually, in case of Cultural Diseases and Disorders it is often the cause of disease and not the symptoms that triggers the treatment. Different cultures have radically different theories regarding the causes of disease. Cooper (2010) suggests that we do not need to decide to treat a culture-bound syndrome as either a distinct category, or as a mere variant of a universally occurring condition. Researchers can legitimately pick and choose, and in different investigations they may employ different classifications. A particular disorder can be both a variant of a universally occurring condition and also it can be considered as a distinct category in its own right. Blease (2010) on the other hand, argues that we should either concede that culture-bound syndromes are formulated in folk theoretical terms, or we should examine the etiology of such episodes by employing scientific methodology and explanations.

In our view, Cultural Diseases and Disorders should be included as a separate category. Even though there may be some overlap in symptoms, the vast majority of Cultural Diseases and Disorders are under-investigated and unknown in Western medicine. Classifying them as some universally recognized illnesses would strip them of their meaning to the cultures in which they appear. However, in some cases of universally recognized ailment is believed to be caused by supernatural forces (e.g. epilepsy caused by a witch). Here we propose to be assigned to both categories: the one corresponding to Cook (1995) and to additional Cultural Diseases and Disorders category.

Another new category, "Ritual/Magical Uses" should be adapted to level 2 states under level 1 state Medicines.

Further level 3 states categories include:

- Festivities/ceremonies: the use of plants as accessories during healing ceremonies, incantations, prayers

Examples:

- In the Colombian Pacific region, Emberá medicine men (Jaibaná) sculpture canes from the stem of the palm Bactris gasipaes Kunth var. gasipaes (Cámara-Leret, unpublished); these canes are an irreplaceable element during their healing ceremonies (Machado C. (2011)) (Fig. 1b).

- In the coastal plane of Ecuador, Tsáchila prepare a decoction from the roots of the palm Bactris gasipaes Kunth var. gasipaes which is used to ritually bathe and purify young shaman apprentices (Cámara-Leret, unpublished).

- Offerings/sacrifices: the use of plants in offerings and sacrifices made to deities who are believed to be responsible for an affliction

Examples:

- In the Colombian Amazon, several Amerindian tribes make symbolic offerings of coca (Erythroxylum coca Lam.) to please the spirits before entering the forest (Rodríguez, 2012) (Fig. 1c).

- In the Andes, the mesa de challa is an offering to Pachamama ('Mother Nature') who protects people from illnesses and brings good luck (Macía et al., 2005). The shrub Loricaria thuyoides (Lam.) Sch. Bip. and palm seeds of Oenocarpus bataua Mart. are commonly used in the mesa de challa among other different products (color wools, sweets, plastic or metal figures). 
- Fetishes/amulets/charms: the use of plants in curative as well as protective/preventive medicines due to its symbolic meaning and/or belief of its' healing powers (not necessarily used in the direct contact with the body)

Examples:

- In the Colombian Amazon, multiple Amerindian tribes use the endocarp of the palm Astrocaryum chambira Burret as an amulet where a "cured" mixture is stored (carayurú); this amulet is carried in the pocket or as a necklace and is used as protection from spirits (Cámara-Leret, unpublished).

- In the coastal plane of Ecuador, Tsáchila medicine men plant the palm Attalea colenda (O.F.Cook) Balslev \& A.J.Hend. near their house to absorb negative energies (Cámara-Leret, unpublished).

- In Bolivia, floors are scrubbed with a decoction prepared from the mixture of 12 spiny plant species to bring good luck (Macía et al., 2005).

- In Southwest China, Bai people hang branches of Prinsepia utilis Royle and Populus sp. on walls and gates to the houses to ward off evil spirits or ghosts (Staub et al., 2011).

- In Europe, it is still believed that always keeping a horse chestnut (Aesculus hippocastanum L.) in the pocket during winter protects against colds (Bellini and Nin, 2005).

- Divination/oracles: the use of plants in explaining the affliction by divination, which is often a large part of the therapy, and necessary to understand the overall significance of a healing process

Examples:

- Palm seeds or kola nuts (Cola sp.) are used as sacred objects/ divination items in oracles, which help to discover the cause of disease; such as the Ifa oracle performed by the Yorubas in Nigeria (Adjanohoun et al., 1988).

- In Colombia, the Kamsá and Inga medicine men employ a tea of the leaves of Iochroma fuchsioides (Bonpl.) Miers as a hallucinogen for diagnosing disease (Schultes and Raffauf, 1990). In the Andean-Amazon piedmont the hallucinogenic vine Banisteriopsis caapi (Spruce ex Griseb.) C.V. Morton is used for divination purposes (Fig. 1d).

- Black magic/bad medicines: folk remedies that are not merely used for curing a disease, but can also be for evil and selfish purposes, and directed to harm others. This may also involve fetishes, oracles (which are other proposed level 3 states) but we suggest it as a separate category to stress the concept of medicine being used for opposite purposes: to harm instead of to heal.

Examples:

- In Ecuador, the lichenized basidiomycete Dictyonema sp. was formerly used in a shamanistic ritual when bad shamans ate it to send a curse to cause other Waoranis to die (Schultes and Raffauf, 1990).

- The Jivaros of Ecuador drink the juice of Nicotiana tabacum L. to perform witchcraft (Schultes and Raffauf, 1990).

Other examples of Ritual/Magical Uses can be found in Smith and Dale (1920); Junod (1927); Harley (1970); Morris (1986); Myren (2011); Mathez-Stiefel et al. (2012); Van Andel et al. (2013).

The EBDCS, as any other standard, aims at creating precise categories to avoid placing the same use in different categories. However, this approach might be more complicated when allocating plant uses in traditional medicine, which is not so unambiguous. Conflict arises when some universal ailments such as infertility are believed to be caused by supernatural forces. Such etiology of disease usually prompts treatments accompanied by rituals. Thus, the ethnobotanical researcher must decide whether the plant remedy used for infertility should be assigned to the Genitourinary System Disorders category, or assigned to the adapted Ritual/Magical Uses category. Placing the plant remedy under either category would only tell part of the story since it would be incomplete to isolate medicinal elements from the mystical treatment process and vice-versa. On the other hand, assigning medico-magical plant use to both categories (the one corresponding to strictly medical terms and the one corresponding to ritual treatment) may appear incorrect since in the user's view it is a sole remedy. Therefore, it is not clear which analytic approach would bring the most accurate solution to this dilemma. Both empirical and spiritual realms should be considered in order to get the complete picture of plant uses in traditional medicine. In our view, such plant uses should be assigned to both categories, the one proposed by Cook (1995) which corresponds to Western medicine, and the new Ritual/Magical Uses category that we propose here, and which reflects traditional medicine foundations.

By duplicating medicinal uses of plants to additional categories of Cultural Diseases and Disorders and Ritual/Magical Uses we will be able to include and understand different etiology of disorders as well as consider magical and ritual elements in traditional medicine analysis. We will also highlight their significance in the treatment process, which otherwise is neglected and omitted. Notably, however, this approach of duplicating the medicomagical plant uses should be revised and carefully applied for quantitative studies where it could cause analytic limitations, and especially for studies quantifying entire plant remedies as a unit, and not individual plant uses. In this case, duplication should only be used at the categories level, complementing the diversity of medicinal plant uses.

Different cultures around the world have different understanding of illnesses and of their relationships with the various spheres of cosmology, including natural, social, and spiritual domains and it would be impossible to put this variation into any standardized system. However, by adapting the proposed changes we can make the standard more complementary for traditional medical system, more valuable and logical from an emic perspective. The proposed categories will also contribute to more comparable studies, saving the endless effort and tedious process of combining data from multiple studies where various protocols were applied. Apart from following data collection standards such as EBDCS, the limitation of comparable databases could effectively be overcome by the repository of ethnomedicinal data, where plant use records are presented in the "rawest" form so they can be explored and efficiently reused by wide range of researchers. Before this goal can be reached, however, an integrative protocol has to be developed and provided with clear use categories that correspond to all possible medicinal plant uses. The categories proposed here will fill the gap of cultural and spiritual aspects of traditional medicine.

\section{References}

Adjanohoun, E.J., Ahyi, A.M.R., Aké Assi, L., Baniakina, J., Chibon, P., Cusset, G., Doulou, V., Enzanza, A., Eymé, J., Goudoté, E., Keita, A., Mbemba, C., Mollet, J., Moutsamboté, J.M., Mpati, J., Sita, P., 1988. Contribution aux études ethnobotaniques et floristiques en République Populaire du Congo. Médecine Traditionelle et Pharmacopée. Agence de Coopération Culturelle et Technique, Paris.

Bellini, E., Nin, S., 2005. Horse chestnut: cultivation for ornamental purposes and non-food crop production. Journal of Herbs, Spices \& Medicinal Plants 11 (1-2), 93-120.

Blease, C., 2010. Scientific progress and the prospects for culture-bound syndromes. Studies in History and Philosophy of Biological and Biomedical Sciences 41, 333-339.

Cámara-Leret, R., Paniagua Zambrana, N.Y., Macía, M.J., 2011. A standard protocol for gathering palm ethnobotanical data and socioeconomic variables across the tropics. In: Medicinal Plants and the Legacy of Richard E. Schultes: Proceedings of the Botany 2011 Symposium Honoring Dr. Richard E. Schultes. pp. 41-71.

Carel, H., Cooper, R., 2010. Introduction: culture-bound syndromes. Studies in History and Philosophy of Biological and Biomedical Sciences 41, 307-308.

Cavender, A.P., Albán, M., 2009. The use of magical plants by curanderos in the Ecuador highlands. Journal of Ethnobiology and Ethnomedicine 5, 3. 
Cook, F., 1995. Economic Botany Data Collection Standard. Prepared for the Interantional Working Group on Taxonomic Databases for Plant Sciences (TDWG). Kew, Royal Botanic Gardens.

Cooper, R., 2010. Are culture-bound syndrome as real as universally-occurring disorders? Studies in History and Philosophy of Biological and Biomedical Sciences 41, 325-332.

Harley, G.W., 1970. Native African Medicine. With special reference to its practice in the Mano tribe in Liberia. Frank Cass \& Co. Ltd., London.

Junod, H.A., 1927. 2nd editionThe Life of a South African Tribe, Vol. II. Macmillan and Co., London.

Landy, D., 1985. A syndrome and its meaning. Science 228 (4701), 850-851.

Lee, R., Balick, M., 2002. Snakebite, shamanism, and modern medicine: exploring the power of the mind-body relationship in healing. Alternative Therapies 8 (3), $114-117$.

Lee, R., Balick, M., 2003. Stealing the soul, soumwahu en naniak, and susto: understanding culturally-specific illnesses, their origins and treatment. Alternative Therapies 9 (3), 106-109.

Machado C., M.L., 2011. La escultura sagrada chocó en el contexto de la memoria de la estética de África y su diaspora: ritual y arte. Universidad Nacional de Colombia, Bogotá p. $323\langle$ http://dare.uva.nl/record/367236〉.

Macía, M.J., García, E., Vidaurre, P.J., 2005. An ethnobotanical survey of medicinal plants commercialized in the markets of La Paz and El Alto, Bolivia. Journal of Ethnopharmacology 97, 337-350.

Macía, M.J., Armesilla, P.J., Cámara-Leret, R., Paniagua-Zambrana, N., Villalba, S., Balslev, H., Pardo-de-Santayana, M., 2011. Palm uses in northwestern South America: a quantitative review. The Botanical Review 77, 462-570.

Mafimisebi, T.E., Oguntade, A.E., 2010. Preparation and use of plant medicines for farmers' health in Southwest Nigeria: socio-cultural, magico-religious and economic aspects. Journal of Ethnobiology and Ethnomedicine 6, 1.

Mathez-Stiefel, S., Vandebroek, I., Rist, S., 2012. Can Andean medicine coexist with biomedical healthcare? A comparison of two rural communities in Peru and Bolivia. Journal of Ethnobiology and Ethnomedicine 8, 26.

Moerman, D.E., 2007. Agreement and meaning: rethinking consensus analysis. Journal of Ethnopharmacology 112, 451-460.
Morris, B., 1986. Herbalism and divination in southern Malawi. Social Science and Medicine 23 (4), 367-377.

Myren, B., 2011. Magic in southern Ghana (BSc thesis). Department of Anthropology, Leiden University, Leiden.

Paniagua-Zambrana, N., Macía, M.J., Cámara-Leret, R., 2010. Toma de datos etnobotánicos de palmeras y variables socioeconómicas en comunidades rurales. Ecología en Bolivia 45 (3), 44-68.

Pretorius, E., 1991. Traditional and modern medicine working in tandem. Cuartionis $14(4), 10-13$.

Rodríguez, C.A., 2012. El Banco del Pensamiento y el Banco de la Negociación. Bogotá, Fondo Patrimonio Natural y Tropenbos Internacional Colombia.

Schultes, R.E., Raffauf., R.F., 1990. The Healing Forest: Medicinal and Toxic Plants of Northwest Amazonia. Dioscorides Press, Portland.

Smith, E.W., Dale, A.M., 1920. The Ila-speaking peoples of Northern Rhodesia, Vol.1. Macmillan and Co., London.

Sofowora, A., 1993. Medicinal Plants and Traditional Medicine in Africa. Spectrum Books, Ibadan, Nigeria.

Sosnowska, J., Balslev, H., 2009. American palm ethnomedicine: a meta-analysis. Journal of Ethnobiology and Ethnomedicine 5, 43.

Staub, P.O., Geck, M.S., Weckerle, C.S., 2011. Incense and ritual plant use in Southwest China: a case study among the Bai in Shaxi. Journal of Ethnobiology and Ethnomedicine 7, 43

Stekelenburg, J., Jager, B.E., Kolk, P.R., Westen, E.H.M.N., ven der Kwaak, A., Wolffers I.N., 2005. Health care seeking behavior and utilization of traditional healers in Kalaboo, Zambia. Health Policy 71, 67-81.

Tempesta, E., 1980. Evaluation of local resources in traditional medicine. Journal of Ethnopharmacology 2, 163-166.

Van Andel, T., Ruysschaert, S., Van de Putte, K., Groenendijk, S., 2013. What makes a plant magical? symbolism and sacred herbs in Afro-Surinamese Winti rituals. In: Voeks, R., Rashford, J. (Eds.), African Ethnobotany in the Americas. Springer, New York, pp. 247-284 (Chapter 10).

WHO, 2000. General Guidelines for Methodologies on Research and Evaluation of Traditional Medicine. Geneva. 